\title{
Relationship among melatonin, postoperative delirium, and postoperative cognitive dysfunction
}

\author{
Shanshan Mu, Yan Wu, Anshi Wu \\ Department of Anesthesiology, Beijing Chao-Yang Hospital, Capital Medical University, Beijing, China \\ Contributions: (I) Conception and design: S Mu, A Wu; (II) Administrative support: S Mu, A Wu; (III) Provision of study materials or patients: S Mu, \\ Y Wu; (IV) Collection and assembly of data: S Mu, Y Wu; (V) Data analysis and interpretation: S Mu, Y Wu; (VI) Manuscript writing: All authors; (VII) \\ Final approval of manuscript: All authors. \\ Correspondence to: Anshi Wu. Department of Anesthesiology, Beijing Chao-yang Hospital, Capital Medical University, 8 Gongren Tiyuchang Nanlu, \\ Chaoyang District, Beijing 100020, China. Email: wuanshi88@163.com.
}

\begin{abstract}
Background Postoperative delirium (POD) and postoperative cognitive dysfunction (POCD) are the most common central nervous system dysfunctions during the perioperative period. Melatonin protects nerve cells and impacts cognitive functioning in patients after surgery.

Methods: A total of 120 patients undergoing elective non-cardiac surgery were evaluated with the confusion assessment method (CAM) for diagnosis of POD on the day before and the $1^{\text {st }}, 2^{\text {nd }}, 3^{\text {rd }}$, and $7^{\text {th }}$ day after surgery. Also, a neuropsychological test for the diagnosis of POCD was performed on the day before and 1 week after surgery. Patients' urine was collected to examine the concentration of 6-sulfatoxymelatonin (6-SMT), the metabolite of melatonin, with the enzyme-linked immunosorbent assay method. Meanwhile, urine creatinine values were examined to calculate the 6-SMT/creatinine ratio (M/C).

Results: The incidence rates of POD and POCD were $7 \%$ and $44 \%$, respectively. There were no statistically differences for the $\mathrm{M} / \mathrm{C}$ on the $1^{\text {st }}, 2^{\text {nd }}, 3^{\text {rd }}$, and $7^{\text {th }}$ day after surgery between the POD and the non-POD groups $(\mathrm{P}>0.05)$. However, there were statistically significant differences $(\mathrm{P}<0.05)$ in the rates of $\mathrm{M} / \mathrm{C}$ change [(preoperative value-postoperative value)/(postoperative value) $\times 100 \%$ ] on the $1^{\text {st }}$ and $7^{\text {th }}$ day after surgery between both groups. Patients were divided into Group $\mathrm{I}_{1}(\geq 100 \%)$ and Group $\mathrm{II}_{1}(<100 \%)$ based on the M/C rate changes on the $1^{\text {st }}$ day, Group $\mathrm{I}_{7}(\geq 200 \%)$ and Group $\mathrm{II}_{7}(<200 \%)$ based on the M/C rate changes on the $7^{\text {th }}$ day, and Group $\mathrm{I}_{\mathrm{w}}(\geq 100 \%)$ and Group $\mathrm{II}_{\mathrm{w}}(<100 \%)$ based on the M/C rate changes during the $1^{\text {st }}$ week after surgery. The incidence rates of POD for Group $\mathrm{I}_{1}$ and Group $\mathrm{II}_{1}$ were $21.1 \%$ and $3.7 \%$, respectively; for Group $\mathrm{I}_{7}$ and Group $\mathrm{II}_{7}$ were $50 \%$ and $1.1 \%$, respectively; for Group $\mathrm{I}_{\mathrm{w}}$ and Group $\mathrm{II}_{\mathrm{w}}$ were $17.2 \%$ and $2.8 \%$, respectively. For 7 patients with POD had POCD, the occurrence of POCD was related to $\mathrm{POD}(\mathrm{P}<0.05)$.
\end{abstract}

Conclusions: Increased melatonin after surgery may be a risk factor for POD. There may be no correlation between melatonin and POCD. POD may be a risk factor of POCD.

Koywords: Melatonin; creatinine; postoperative cognitive dysfunction (POCD); postoperative delirium (POD); 6-sulfatoxymelatonin (6-SMT)

Submitted Jun 16, 2021. Accepted for publication Sep 09, 2021.

doi: 10.21037/apm-21-2001

View this article at: https://dx.doi.org/10.21037/apm-21-2001

\section{Introduction}

Central nervous system dysfunction often occurs in elderly patients after anesthesia and surgery. Postoperative delirium (POD) and postoperative cognitive dysfunction (POCD) are more important and common complications.

POD is defined by an acute, transient, and nonspecific change in the level of consciousness, attention, cognition, perception and sleep-wake cycle $(1,2)$. According to a report 
of the American Psychiatric Association, the incidence of POD is as high as $51 \%(3,4)$. And the incidence of the elderly is $15-53 \%$ (5). POCD is defined as nervous system complications after surgery in patients who had no mental disorders, such as anxiety, personality changes, or memory impairment before surgery. The incidence of POCD is $25.8 \%$ at 1 week after surgery and $9.9 \%$ at 3 months (6), and is up to $30 \%$ for orthopedic surgery (7). Melatonin can protect nerve cells through its antioxidant and antiapoptotic effects. At the same time, melatonin can regulate the light-dark cycle, produce a hypnotic effect, and improve sleep quality.

Sleep disorders are common in patients after surgery. The lack of synchronization between sleep-wake cycle and melatonin secretion can lead to the occurrence of POD (8). However, related studies do not illuminate the relationship among melatonin, POD, and POCD. Therefore, this study aimed to assess the incidence of POD and POCD in patients undergoing non-cardiac surgery, who are 60 years old and over and to assess the concentration of melatonin by detecting its urinary metabolite (6-sulfatoxymelatonin, 6-SMT) before and after surgery. As such the study seeks to determine the relationships among melatonin, POD, and POCD, and to assess if melatonin can indicate postoperative cognitive impairment. We present the following article in accordance with the STROBE reporting checklist (available at https://dx.doi.org/10.21037/apm-21-2001).

\section{Methods}

\section{Subject enrollment}

All procedures performed in this study involving human participants were in accordance with the Declaration of Helsinki (as revised in 2013). The study was approved by the Medical Ethics Committee of Beijing Chaoyang Hospital, Beijing, China, and informed consent was obtained from all the patients. Older patients, aged $60-82$ years, who were scheduled for non-cardiac surgery that was expected to last $2 \mathrm{~h}$ or longer, were recruited sequentially to this study. Exclusion criteria included: a score of $\leq 23$ on the Mini-Mental State Examination (MMSE) before surgery, $\leq 6$ years of education, a current or past history of psychiatric or neurological disease, kidney dysfunction, visual or auditory disorders, alcohol or drug dependence, regular use of tranquilizers or antidepressants and a history of open cardiac surgery or intracranial surgery. Patients were also excluded if they were not available to complete the neurocognitive test 1 week after surgery.

\section{Perioperative management}

A preoperative evaluation was conducted 1 day before surgery and included the patient's age, gender, whether had regular schedule recently, past medical history, physical examination results, education level, recent medication history, surgical history, and the visual analog scale (VAS) score before surgery. The VAS score is in relation to the degree of pain.

All patients received general anesthesia or combined spinalepidural anesthesia (CSEA). General anesthesia was induced by using $1-2 \mathrm{mg} / \mathrm{kg}$ of midazolam, 15-25 $\mu \mathrm{g}$ of sufentanil, $1.5-2.5 \mathrm{mg} / \mathrm{kg}$ of propofol, and $0.6 \mathrm{mg} / \mathrm{kg}$ of rocuronium and was maintained with $0.01-0.02 \mathrm{mg} / \mathrm{kg} / \mathrm{h}$ and $6-15 \mathrm{mg} / \mathrm{kg} / \mathrm{h}$ of propofol during the operation. Patients were extubated in the operating room after surgery. Combined spinal-epidural anesthesia was administered at the L2-3 or L3-4 interspace using $1 \%$ ropivacaine, followed by insertion of an epidural catheter. Patients received patient-controlled analgesia (PCA) for postoperative pain control of their own accord. None of the patients received atropine before surgery nor were any inhalation anesthetics administered during the operation.

Intraoperative and postoperative observations included the way the operation was conducted, the anesthesia that were administered, duration of the operation and anesthesia, intraoperative and arterial blood gas analysis, blood pressure, blood loss, fluid infusion, blood products, urine output, medicines used intraoperatively and their dosage, the use of PCA, VAS score, and postoperative complications. Patients were assessed daily during their hospital stay to review their medical records.

Patients were tested 1 day before the operation and on the $1^{\text {st }}, 2^{\text {nd }}, 3^{\text {rd }}$, and $7^{\text {th }}$ day after surgery with the confusion assessment method (CAM) for the diagnosis of POD. They were also tested 1 day before the operation and 1 week after surgery with a neuropsychological test for the diagnosis of POCD. In total, 10 neuropsychological tests (9-12) were used to assess the memory and executive functions of the patients. The 10 tests included The Mini-Mental Stage Examination (MMSE), Hopkins Verbal Learning Test (HVLT), HVLT (Delayed Recall), Brief Visualspatial Memory Test (BVMT), BVMT (Delayed Recall), Trail Making Test (TMT), Digit Span Test (DST), Benton Judgment of Line Orientation, Digit symbol-coding Test and List Delayed Recognition (13). Before testing, the Beck Depression Inventory Test was used to exclude depressed patients. 


\section{Diagnostic criteria}

The definition of POD was based on the Diagnostic and Statistical Manual of Mental Disorders, 4th Edition (DSM-IV) criteria (14). We used the American Psychiatric Association's CAM (15) to screen for cases of possible delirium and then confirmed if DSM-IV criteria were met. Mental health status information was also collected from nursing reports.

The diagnostic criteria from ISPOCD study were used for determining POCD of patient $(6,12)$. Fifty age-matched adults who were not hospitalized and did not receive surgery (control group) were involved in the neuropsychological tests. The standard deviation (SD) value was obtained. A $\mathrm{Z}$ score was calculated by comparing differences between preoperative and 1-week postoperative score to control group $(6,12)$. POCD was diagnosed when $Z$ score $>1.96$ of more than 1 test.

\section{Collection and detection of urine samples}

Morning urine samples were obtained from the enrolled patients one day before surgery and on the $1^{\text {st }}, 2^{\text {nd }}, 3^{\text {rd }}$, and $7^{\text {th }}$ day after surgery. Each urine sample was collected before breakfast. The urine supernatant was obtained using low-speed centrifugation, and the supernatant samples were stored in a sealed sterile container at $-80{ }^{\circ} \mathrm{C}$ before testing. We tested the 6-SMT level in the supernatant samples using enzyme-linked immune sorbent assay (ELISA, Elisa kits: Immuno-Biological Laboratories, Minneapolis, MN, USA). In recognition that urine samples are highly diluted because of postoperative infusion, urine creatinine concentrations were utilized to adjust the urine samples' 6-SMT concentrations (16). The 6-SMT/ creatinine ratio $(\mathrm{M} / \mathrm{C}=6-\mathrm{SMT} /$ creatinine $\times 1,000)$ was used to provide a more objective estimate of urine 6-SMT concentration. For convenience, we will refer to this as the "6-SMT concentration" instead of the "adjusted 6-SMT concentration", unless otherwise stated. In addition, we detected the urine creatinine values in the same original urine samples. Assays of urine creatinine were carried out using a UniCel ${ }^{\circledR}$ DxC 800 Synchron ${ }^{\circledR}$ Clinical System (Beckman, Brea, CA, USA).

\section{Statistical analysis}

Statistical analyses were performed with SPSS for Windows (Version 16.0). Normally distributed measurement data were analyzed with independent-sample $t$-tests, while nonnormally distributed data were analyzed with a rank sum test. Categorical data were analyzed using chi-square tests $\left(\chi^{2}\right)$. A P value of $<0.05$ was considered as indicating a statistically significant difference.

\section{Results}

\section{The incidence of POD and POCD}

A total of 120 patients were recruited to this study, of whom 100 patients were assessed throughout. Seven patients were diagnosed with POD, and as such, the incidence of POD was $7 \%$. Forty-four patients were diagnosed with POCD, and hence the incidence of POCD was $44 \%$. The general characteristics of patients in the groups with and without POD are shown in Table 1. There were no significant differences among the groups.

\section{The rates of $M / C$ change}

The patients were divided into the POD and non-POD groups based on the occurrence of POD. The M/C before surgery and on the $1^{\text {st }}, 2^{\text {nd }}, 3^{\text {rd }}$, and $7^{\text {th }}$ day after surgery were compared between the two groups and there were no statistically significant differences $(\mathrm{P}>0.05)$. However, the rates of $\mathrm{M} / \mathrm{C}$ change [the value of change $=$ (preoperative value - postoperative value)/postoperative value $\times 100 \%$ ] of the POD group compared to the non-POD group on the $1^{\text {st }}$ and $7^{\text {th }}$ day after surgery were significantly different ( $\mathrm{P}$ values were 0.024 and 0.004 , respectively; Figure 1); and there were no statistically significant differences for the other days. Each time point of M/C and the rates of change are shown in Table 2. The "rate of change" is defined as the maximum of the rate of $\mathrm{M} / \mathrm{C}$ change on the $1^{\text {st }}, 2^{\text {nd }}, 3^{\text {rd }}$, and $7^{\text {th }}$ day after surgery.

\section{The incidence of POD in high fluctuations on the $1^{\text {st }}$ day after surgery}

The patients were divided into Group $\mathrm{I}_{1}$ and Group $\mathrm{II}_{1}$ based on the magnitude of the $\mathrm{M} / \mathrm{C}$ rate changes on the $1^{\text {st }}$ day after surgery (Group $\mathrm{I}_{1}$ was defined as patients whose $\mathrm{M} / \mathrm{C}$ change $\geq 100 \%$, the rest were allocated to Group $\mathrm{II}_{1}$ ). The incidence rate of POD of Group $\mathrm{I}_{1}$ was $21.1 \%$, which is higher than the $3.7 \%$ of Group $\mathrm{II}_{1}(\mathrm{P}=0.03)$. There was no statistically significant difference between the two groups (Figure 2). 
Table 1 General condition of patients with and without postoperative delirium and patients with and without postoperative cognitive dysfunction

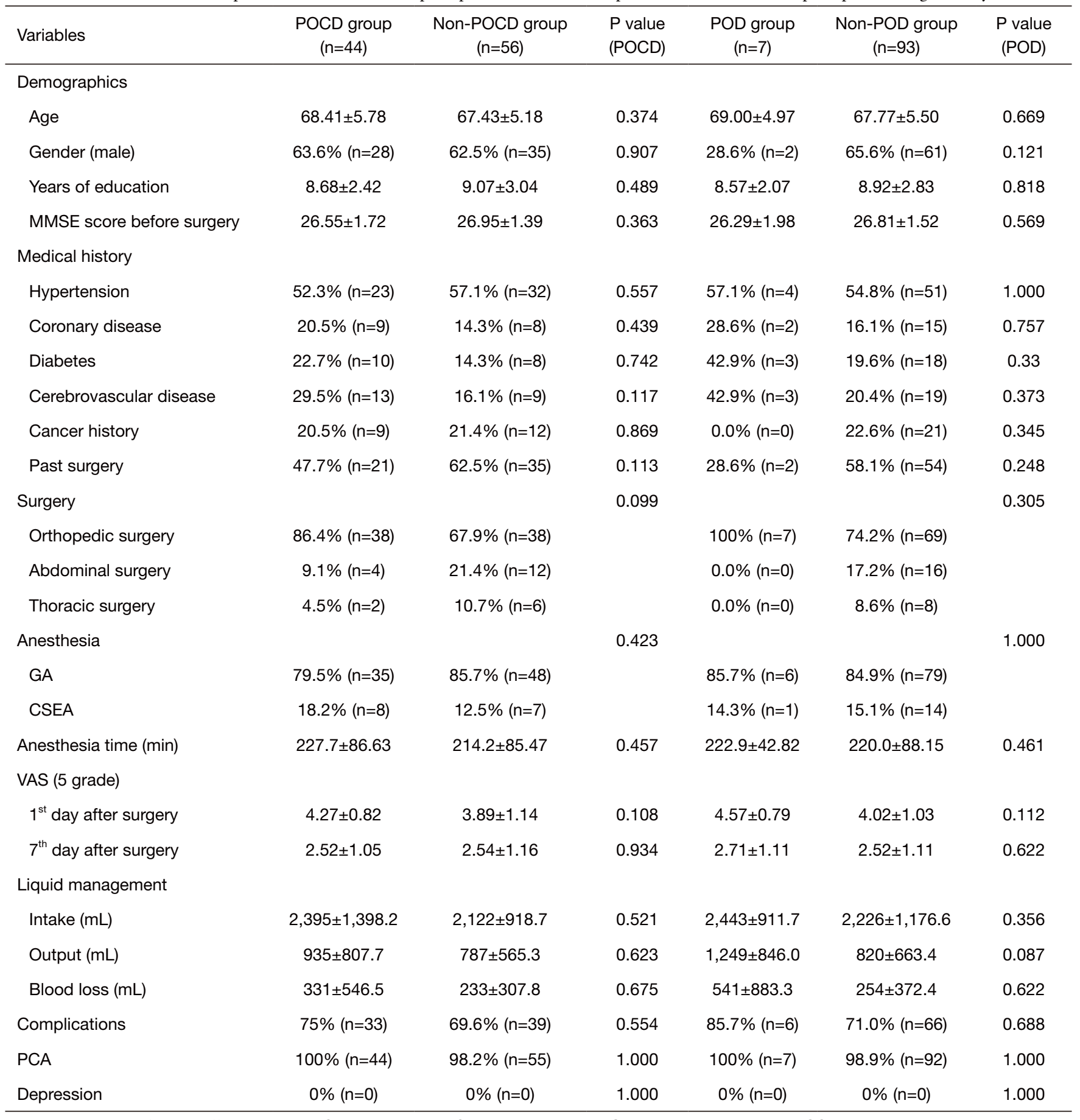

$\mathrm{P}>0.05$, no significant differences. MMSE, Mini-Mental State Examination; GA, general anesthesia; CSEA, combined spinal-epidural anesthesia; VAS, visual analogue scale; POD, postoperative delirium; POCD, postoperative cognitive dysfunction. 


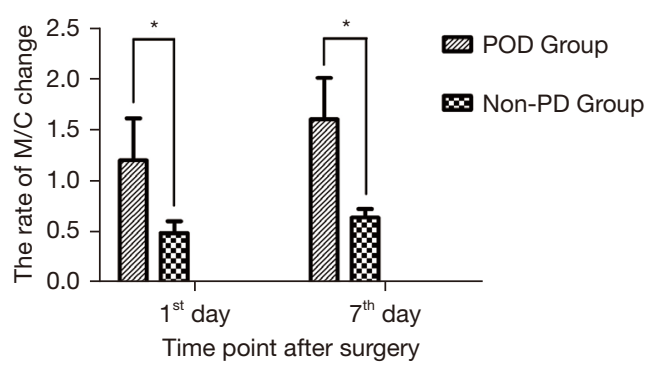

Figure 1 The rates of $M / C$ in the postoperative delirium and nonpostoperative delirium groups. *, $\mathrm{P} 1=0.024, \mathrm{P} 7=0.004$, there is a statistical significance. POD, postoperative delirium; M/C, the 6-SMT/creatinine ratio.

\section{The incidence of POD in high fluctuations on the $7^{\text {th }}$ day after surgery}

If the $\mathrm{M} / \mathrm{C}$ rate changed on the $7^{\text {th }}$ day after surgery, the sample was divided into two groups analogously to the $1^{\text {st }}$ day after the operation; however, there were statistically significant differences. Group $\mathrm{I}_{7}$ was defined as patients whose $M / C$ change $\geq 200 \%$, and the rest were allocated to Group $\mathrm{II}_{7}$. The incidence of POD of Group $\mathrm{I}_{7}$ was $50 \%$, which is much higher than the $1.1 \%$ of Group $\mathrm{II}_{7}(\mathrm{P}=0.000)$. There were no statistically significant differences between the two groups (Figure 3).

\section{The incidence of POD in bigh fluctuations during the first week after surgery}

Considering the occurrence of POD might relate to the overall change of 6-SMT across the 4 time points after surgery, the patients were divided into Group $\mathrm{I}_{\mathrm{w}}$ and Group $\mathrm{II}_{\mathrm{w}}$ based on the magnitude of $\mathrm{M} / \mathrm{C}$ rate changes during the $1^{\text {st }}$ week after surgery (Group $\mathrm{I}_{\mathrm{w}}$ was defined as patients whose $\mathrm{M} / \mathrm{C}$ change $\geq 100 \%$, the rest were allocated to Group $\mathrm{II}_{\mathrm{w}}$ ). The incidence of POD of Group $\mathrm{I}_{\mathrm{w}}$ was $17.2 \%$, which is higher than the $2.8 \%$ for Group $\mathrm{II}_{\mathrm{w}}(\mathrm{P}=0.033)$. There was a statistically significant difference between the two Groups (Figure 4).

\section{The incidence of POCD in the POD groups}

Patients were divided into the POCD and non-POCD groups based on the occurrence of POCD. The M/C and the rates of change before surgery, and on the $1^{\text {st }}, 2^{\text {nd }}$, $3^{\text {rd }}$, and $7^{\text {th }}$ day after surgery were compared between the two groups, and there were no statistically significant differences $(\mathrm{P}>0.05$, Table 3$)$.

Seven patients with POD also had POCD. Patients were divided into the POD and non-POD groups based on the occurrence of POD. The incidence of POCD in the POD group was $100 \%$, which is much higher than nonPOD group's incidence of $39.8 \%$. This suggests that the occurrence of $\mathrm{POCD}$ was related to $\mathrm{POD}(\mathrm{P}<0.05$, Figure 5$)$.

\section{Discussion}

Past research has confirmed that the people over the age of 70 years have a significantly increased risk of POD $(17,18)$. At the same time, advanced age is the only specific risk factor for POCD (19). The changes that accompany aging influence the individual's ability to withstand the stress of injury, surgery, and anesthesia. Therefore, we chose patients over 60 years old as research objects.

In total, seven patients met the diagnostic criteria of POD according to the CAM during the $1^{\text {st }}$ to $7^{\text {th }}$ day after surgery. The incidence of POD was $7 \%$, which is lower than what is reported by previous studies. It may relate to the following factors. First, the patients recruited in this experiment were able to complete the neuropsychological assessments for POCD, and people with very low cognitive dysfunction were excluded from the study. Second, those who could not concentrate for a long time because of their low education levels, preoperative cognitive dysfunction and advanced ages were excluded from the study too. In addition, the reasons for the low incidence may be that CAM evaluations were conducted and diagnoses of patients with reduced activity types and mixed types of POD may have been missed.

The results of this study show that patients with high secretion level of melatonin after surgery were more susceptible to POD, especially on the $1^{\text {st }}$ and $7^{\text {th }}$ day. On the $1^{\text {st }}$ day after surgery, the effects of surgery and anesthesia and postoperative pain are strongest in those most affected, and patients are susceptible to POD. During this period, as long as the increase of melatonin is up to two times or more of preoperative levels, patients have a higher risk of POD. On the $7^{\text {th }}$ day after surgery the convalescence of the patients' physical condition and mental state is completed. During this period, the incidence of POD is reduced greatly compared to the $1^{\text {st }}$ day after surgery, such that patients are susceptible to POD when the melatonin increases up to three times or more than the preoperative levels.

Shigeta and colleagues (20) studied the perioperative fluctuation of melatonin in 29 patients who underwent 
Table 2 The 6-SMT/creatinine ratio and the rates of change at each time point in the postoperative delirium and non-postoperative delirium groups

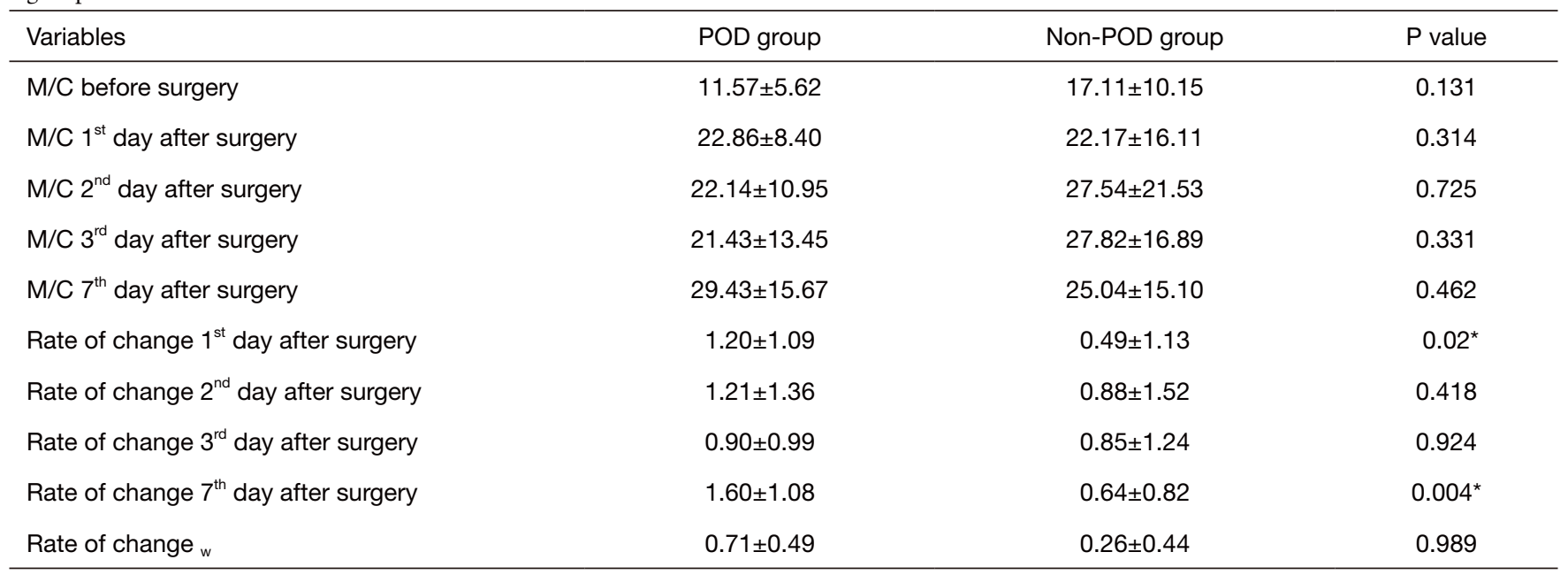

${ }^{*}, \mathrm{P}<0.05$, there is a statistical significance. $\mathrm{POD}$, postoperative delirium; $\mathrm{M} / \mathrm{C}$, the $6-\mathrm{SMT} /$ creatinine ratio.

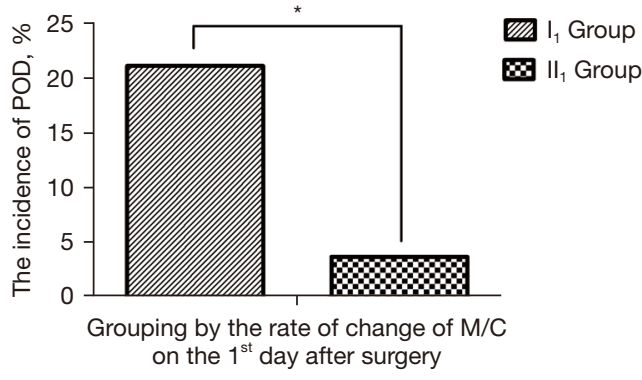

Figure 2 The incidence of postoperative delirium in high fluctuations on the $1^{\text {st }}$ day after surgery. Patients were divided into Group $\mathrm{I}_{1}(\geq 100 \%)$ and Group $\mathrm{II}_{1}(<100 \%)$ based on the $\mathrm{M} / \mathrm{C}$ rate changes on the $1^{\text {st }}$ day. ${ }^{*}, \mathrm{P}=0.03$, there is statistical significance. POD, postoperative delirium; M/C, the 6-SMT/creatinine ratio.

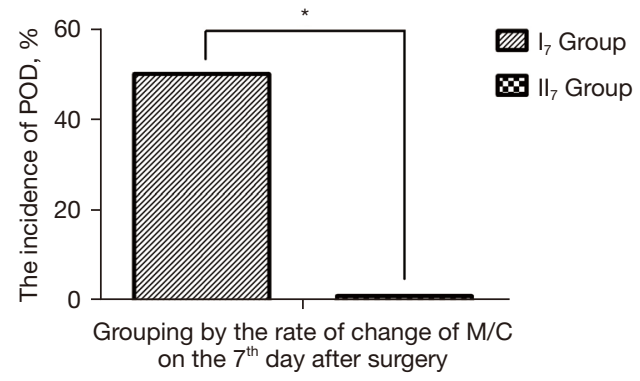

Figure 3 The incidence of post-operative delirium in high fluctuations on the $7^{\text {th }}$ day after surgery. Group $I_{7}(\geq 200 \%)$ and Group $\mathrm{II}_{7}(<200 \%)$ based on the M/C rate changes on the $7^{\text {th }}$ day. *, $\mathrm{P}=0.000$, there is a statistical significance. $\mathrm{POD}$, postoperative delirium; M/C, the 6-SMT/creatinine ratio.

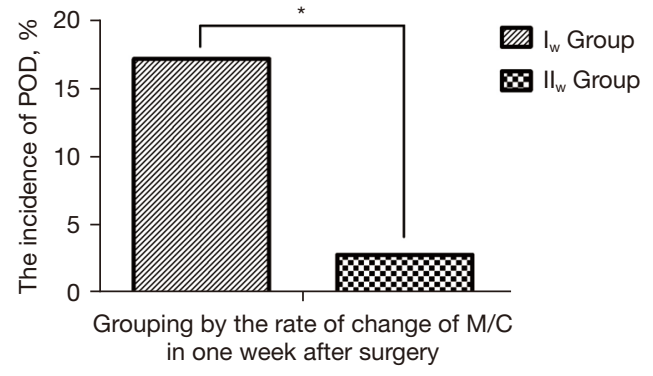

Figure 4 The incidence of postoperative delirium in high fluctuations during the first week after surgery. Group $\mathrm{I}_{\mathrm{w}}(\geq 100 \%)$ and Group $\mathrm{II}_{\mathrm{w}}(<100 \%)$ based on the $\mathrm{M} / \mathrm{C}$ rate changes during the $1^{\text {st }}$ week. *, $\mathrm{P}=0.033$, there is a statistical significance. POD, postoperative delirium; M/C, the 6-SMT/creatinine ratio.

abdominal surgery. The results showed that melatonin levels after surgery were lower than before surgery in patients without complications, which was in contrast to patients with complications. Balan and colleagues' study (21) showed melatonin levels were related to the subtype of POD: and that patients with hyperactive POD had a significant decrease of melatonin during the acute period compared to during their convalescence, but that the mixed type showed no obvious changes. We attempted to further explore this, but too few patients with POD diagnosed were included in the sample to assess the effects of this subtype. A larger sample size would be required to prove this.

Some authors consider using melatonin to prevent and 
Table 3 The 6-SMT/creatinine ratio and the rate of change in each time point in the postoperative cognitive dysfunction and non-postoperative cognitive dysfunction groups

\begin{tabular}{|c|c|c|c|}
\hline Variables & POCD group & Non-POCD group & $P$ value \\
\hline $\mathrm{M} / \mathrm{C} 1^{\text {st }}$ day after surgery & $21.89 \pm 17.21$ & $22.51 \pm 14.33$ & 0.417 \\
\hline$M / C 2^{\text {nd }}$ day after surgery & $23.83 \pm 12.55$ & $30.11 \pm 26.06$ & 0.592 \\
\hline $\mathrm{M} / \mathrm{C} 3^{\text {rd }}$ day after surgery & $24.19 \pm 11.91$ & $30.19 \pm 19.70$ & 0.073 \\
\hline Rate of change $1^{\text {st }}$ day after surgery & $0.54 \pm 1.31$ & $0.53 \pm 0.97$ & 0.220 \\
\hline Rate of change $2^{\text {nd }}$ day after surgery & $0.64 \pm 0.91$ & $1.13 \pm 1.86$ & 0.574 \\
\hline Rate of change $3^{\text {rd }}$ day after surgery & $0.65 \pm 0.85$ & $1.04 \pm 1.45$ & 0.106 \\
\hline Rate of change $7^{\text {th }}$ day after surgery & $0.71 \pm 0.86$ & $0.71 \pm 0.89$ & 0.994 \\
\hline
\end{tabular}

$\mathrm{P}>0.05$, no significant differences. POCD, postoperative cognitive dysfunction; M/C, the 6-SMT/creatinine ratio.

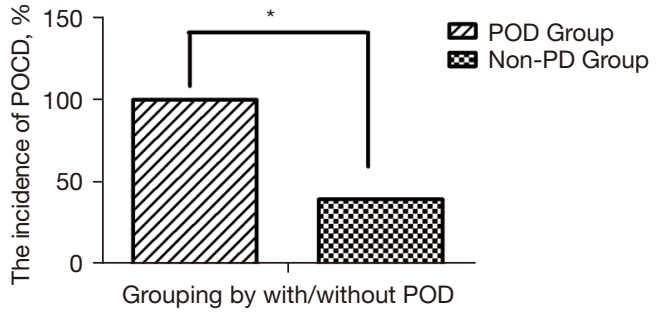

Figure 5 The incidence of postoperative cognitive dysfunction in the postoperative delirium and non-postoperative delirium groups. *, $\mathrm{P}=0.007$, there is a statistical significance. POD, postoperative delirium; POCD, postoperative cognitive dysfunction.

treat POD in older patients, because of the relationship between melatonin and POD. So far, there was case report that confirmed melatonin was effective in preventing and treating POD (22). Campbell and colleagues' metaanalysis (23) also showed that perioperative melatonin reduced the incidence of delirium in older adults in the included studies. However, Ford and colleagues' randomized double-blind placebo-controlled trial in major cardiac surgery (24) did not support the use of melatonin to prevent delirium after major cardiac surgery. Also a meta-analysis (25) also showed there was no clear evidence that a melatonin agonist or melatonin reduced the incidence of delirium. Therefore, whether melatonin can be used to prevent POD remains to be investigated.

Forty-four patients were diagnosed with POCD on the $7^{\text {th }}$ day after surgery. The incidence of POCD was $44 \%$, which was a little higher than the occurrence reported by other authors (7). Our findings may relate to the type of surgery: $76 \%$ patients enrolled in this study had undergone orthopedic surgery. Maybe the following reasons can explain it: in orthopedic surgeries, the duration of operations is longer, the dosage of anesthetic is accordingly increased, the postoperative pain is serious, and the stress and inflammatory reactions are also more serious than in other non-cardiac surgery. The most important reason is that in orthopedic surgery can produce intracerebral adipose microembolus (26-28), which can lead to cerebral embolism. In addition, this study employed a widely used internationally validated neuropsychology test to assess patients. It decreased the occurrence of ceiling and learning effects brought by the MMSE assessment, thus increasing the detection rate of POCD.

This study showed that melatonin was not related to the occurrence of POCD. The relationship between melatonin and the occurrence of POCD has not been confirmed by previous research. In recent years, several animal experiments (29) revealed isoflurane might influence the plasma concentration of melatonin and the expression of melatonin receptors 1 and 2 (MT1/MT2), which could lead to memory function impairment in aged rats. Melatonin might reduce memory impairment in aged rats through regulating the plasma concentration of melatonin and melatonin receptor expression. The methods used in $\mathrm{Wu}$ and colleagues' study (13) are similar to the ones used in this study: urine samples were collected in the morning before 
surgery and on the $1^{\text {st }}, 2^{\text {nd }}$, and $7^{\text {th }}$ day after surgery to detect the concentrations of urinary 6-SMT, and patients were tested with neuropsychological assessments before surgery and 1 week after surgery to diagnose POCD. The results showed the incidence of POCD was significantly increased in the group whose concentration of urinary 6-SMT significantly fluctuated before and after surgery. However, the conclusions are opposite to each other. Gögenur and colleagues' study (30) showed that the concentration of 6-SMT exhibits the same changes after surgery compared with before surgery in all patients with high secretion during the daytime and low secretion during the nighttime. Although patients with POCD had poor quality of sleep and woke up more frequently during the night, their secretion of 6-SMT showed no significant differences, regardless of whether it was daytime or nighttime or the total 24 hours were included. The secretion of melatonin is affected by the rhythm of the sleep cycle. It is 5 to 10 times during the nighttime compared with the daytime and reaches a peak value at $2 \mathrm{AM}$ to $3 \mathrm{AM}$ in the morning (31). At the same time, the secretion is affected by the physical condition and external factors. Therefore, completely opposite results are not unexpected.

Because attention is important for all neuropsychology tests, delirium state and POCD are not two independent states. In some cases, POD might be an important risk factor for POCD (20). In addition, some studies have shown that the incidence of early POCD was higher in patients with POD (32). The statement above is consistent with this study. Seven patients with POD had POCD in our study, which shows that POD and POCD are closely related. The purpose of the treatment of POD and POCD is to quickly relieve the clinical symptoms and strive for the best long-term prognosis. The main treatment measures include non-drug treatment and drug treatment. Non-drug treatment is usually considered first, and drug treatment is suitable for patients with agitated delirium. An important step is to discover and clarify the pathogenesis of delirium patients, such as pain, sleep deprivation or disruption of sleep rhythm, malnutrition or sensory disorders, or infections. Generally, if these risk factors are found, the risk factors need to be treated. At the same time, check the patient's medication status on the day, screen out the drugs that may cause delirium, stop or use alternative medications. The limitation of this study is its insufficient sample size, which means the results are not very convincing. We should increase the sample size to get more accurate results.

\section{Conclusions}

The incidence of POD and POCD is 7\% and 44\%, respectively, in non-cardiac surgery patients. Melatonin increases after surgery may be a risk factor for POD. There may be no correlation between melatonin and POCD. POD may be a risk factor for POCD.

\section{Acknowledgments}

Funding: None.

\section{Footnote}

Reporting Checklist: The authors have completed the STROBE reporting checklist. Available at https://dx.doi. org/10.21037/apm-21-2001

Data Sharing Statement: Available at https://dx.doi. org/10.21037/apm-21-2001

Conflicts of Interest: All authors have completed the ICMJE uniform disclosure form (available at https://dx.doi. org/10.21037/apm-21-2001). The authors have no conflicts of interest to declare.

Ethical Statement: The authors are accountable for all aspects of the work in ensuring that questions related to the accuracy or integrity of any part of the work are appropriately investigated and resolved. All procedures performed in this study involving human participants were in accordance with the Declaration of Helsinki (as revised in 2013). This study was approved by the Medical Ethics Committee of Beijing Chaoyang Hospital, Beijing, China. Clinical records in our study were used with the informed consent of each participant.

Open Access Statement: This is an Open Access article distributed in accordance with the Creative Commons Attribution-NonCommercial-NoDerivs 4.0 International License (CC BY-NC-ND 4.0), which permits the noncommercial replication and distribution of the article with the strict proviso that no changes or edits are made and the original work is properly cited (including links to both the formal publication through the relevant DOI and the license). 
See: https://creativecommons.org/licenses/by-nc-nd/4.0/.

\section{References}

1. Bryson GL, Wyand A. Evidence-based clinical update: general anesthesia and the risk of delirium and postoperative cognitive dysfunction. Can J Anaesth 2006;53:669-77.

2. Ming $\mathrm{S}$, Zhang $\mathrm{X}$, Gong $Z$, et al. Perioperative dexmedetomidine and postoperative delirium in noncardiac surgery: a meta-analysis. Ann Palliat Med 2020;9:264-71.

3. Edelstein DM, Aharonoff GB, Karp A, et al. Effect of postoperative delirium on outcome after hip fracture. Clin Orthop Relat Res 2004;(422):195-200.

4. Rahkonen T, Mäkelä H, Paanila S, et al. Delirium in elderly people without severe predisposing disorders: etiology and 1-year prognosis after discharge. Int Psychogeriatr 2000;12:473-81.

5. Koch S, Radtke F, Spies C. A call for a more rigorous screening of postoperative delirium. Ann Transl Med 2019;7:S192.

6. Moller JT, Cluitmans P, Rasmussen LS, et al. Longterm postoperative cognitive dysfunction in the elderly ISPOCD1 study. ISPOCD investigators. International Study of Post-Operative Cognitive Dysfunction. Lancet 1998;351:857-61.

7. Salazar F, Doñate $M$, Boget $T$, et al. Intraoperative warming and post-operative cognitive dysfunction after total knee replacement. Acta Anaesthesiol Scand 2011;55:216-22.

8. Wright KP Jr, Hull JT, Hughes RJ, et al. Sleep and wakefulness out of phase with internal biological time impairs learning in humans. J Cogn Neurosci 2006;18:508-21.

9. Bekker A, Lee C, de Santi S, et al. Does mild cognitive impairment increase the risk of developing postoperative cognitive dysfunction? Am J Surg 2010;199:782-8.

10. Hudetz JA, Patterson KM, Iqbal Z, et al. Metabolic syndrome exacerbates short-term postoperative cognitive dysfunction in patients undergoing cardiac surgery: results of a pilot study. J Cardiothorac Vasc Anesth 2011;25:282-7.

11. Jensen B, Rasmussen LS, Steinbrüchel DA. Cognitive outcomes in elderly high-risk patients 1 year after off-pump versus on-pump coronary artery bypass grafting. A randomized trial. Eur J Cardiothorac Surg 2008;34:1016-21.

12. Rasmussen LS, Larsen K, Houx P, et al. The assessment of postoperative cognitive function. Acta Anaesthesiol Scand 2001;45:275-89.

13. Wu Y, Wang J, Wu A, et al. Do fluctuations in endogenous melatonin levels predict the occurrence of postoperative cognitive dysfunction (POCD)? Int J Neurosci 2014;124:787-91.

14. Lewis G. DSM-IV. Diagnostic and statistical manual of mental disorders, 4th edn - American Psychiatric Association; 1996.

15. Practice guideline for the treatment of patients with delirium. American Psychiatric Association. Am J Psychiatry 1999;156:1-20.

16. Elkins HB, Pagnotto LD, Smith HL. Concentration adjustments in urinalysis. Am Ind Hyg Assoc J 1974;35:559-65.

17. Smith MJ, Breitbart WS, Platt MM. A critique of instruments and methods to detect, diagnose, and rate delirium. J Pain Symptom Manage 1995;10:35-77.

18. Levkoff SE, Evans DA, Liptzin B, et al. Delirium. The occurrence and persistence of symptoms among elderly hospitalized patients. Arch Intern Med 1992;152:334-40.

19. Monk TG, Weldon BC, Garvan CW, et al. Predictors of cognitive dysfunction after major noncardiac surgery. Anesthesiology 2008;108:18-30.

20. Shigeta H, Yasui A, Nimura Y, et al. Postoperative delirium and melatonin levels in elderly patients. Am J Surg 2001;182:449-54.

21. Balan S, Leibovitz A, Zila SO, et al. The relation between the clinical subtypes of delirium and the urinary level of 6-SMT. J Neuropsychiatry Clin Neurosci 2003;15:363-6.

22. Hanania M, Kitain E. Melatonin for treatment and prevention of postoperative delirium. Anesth Analg 2002;94:338-9.

23. Campbell AM, Axon DR, Martin JR, et al. Melatonin for the prevention of postoperative delirium in older adults: a systematic review and meta-analysis. BMC Geriatr 2019;19:272.

24. Ford AH, Flicker L, Kelly R, et al. The Healthy HeartMind Trial: Randomized Controlled Trial of Melatonin for Prevention of Delirium. J Am Geriatr Soc 2020;68:112-9.

25. Siddiqi N, Harrison JK, Clegg A, et al. Interventions for preventing delirium in hospitalised non-ICU patients. Cochrane Database Syst Rev 2016;3:CD005563.

26. Edmonds CR, Barbut D, Hager D, et al. Intraoperative cerebral arterial embolization during total hip arthroplasty. Anesthesiology 2000;93:315-8.

27. Byrick RJ. Causes of brain injury during orthopedic surgery. Can J Anaesth 2004;51:867-70. 
28. Riding G, Daly K, Hutchinson S, et al. Paradoxical cerebral embolisation. An explanation for fat embolism syndrome. J Bone Joint Surg Br 2004;86:95-8.

29. Liu Y, Ni C, Tang Y, et al. Melatonin attenuates isofluraneinduced acute memory impairments in aged rats. Basic Clin Pharmacol Toxicol 2013;113:215-20.

30. Gögenur I, Middleton B, Burgdorf S, et al. Impact of sleep and circadian disturbances in urinary 6-sulphatoxymelatonin levels, on cognitive function after

Cite this article as: $\mathrm{Mu} \mathrm{S}, \mathrm{Wu} \mathrm{Y,} \mathrm{Wu} \mathrm{A}$. Relationship among melatonin, postoperative delirium, and postoperative cognitive dysfunction. Ann Palliat Med 2021;10(9):9443-9452. doi: 10.21037/ apm-21-2001 major surgery. J Pineal Res 2007;43:179-84.

31. Champney TH, Holtorf AP, Steger RW, et al. Concurrent determination of enzymatic activities and substrate concentrations in the melatonin synthetic pathway within the same rat pineal gland. J Neurosci Res 1984;11:59-66.

32. Rudolph JL, Marcantonio ER, Culley DJ, et al. Delirium is associated with early postoperative cognitive dysfunction. Anaesthesia 2008;63:941-7. 